\title{
Le groupe de réflexion sur les conditions d'exercice des professions de communication
}

Hugues Hotier

\section{(2) OpenEdition}

1 Journals

Édition électronique

URL : http://journals.openedition.org/communicationorganisation/1567

DOI : 10.4000/communicationorganisation. 1567

ISSN : $1775-3546$

Éditeur

Presses universitaires de Bordeaux

Édition imprimée

Date de publication : 1 mai 1992

ISSN : 1168-5549

Référence électronique

Hugues Hotier, «Le groupe de réflexion sur les conditions d'exercice des professions de communication », Communication et organisation [En ligne], 1 | 1992, mis en ligne le 26 mars 2012 consulté le 26 avril 2019. URL : http://journals.openedition.org/communicationorganisation/1567 ; DOI : 10.4000/communicationorganisation. 1567

Ce document a été généré automatiquement le 26 avril 2019

(c) Presses universitaires de Bordeaux 


\title{
Le groupe de réflexion sur les conditions d'exercice des professions de communication
}

\author{
Hugues Hotier
}

1 Tout a commencé avec le colloque que Le Monde et le Groupe de Recherche en Communication des Organisations de l'Université de Bordeaux 3 consacrèrent, en octobre 1990, aux rapports entre la communication et l'éthique. Les conclusions de cette manifestation qui réunissait quelque deux cents professionnels et chercheurs devaient mettre en lumière la nécessité d'assurer aux chargés de communication des entreprises une protection déontologique mais aussi juridique.

L'argumentation exprimée alors peut être résumée ainsi que suit :

1. Dans l'exercice de son métier, le journaliste jouit d'une double protection. La déontologie de la profession a créé une coutume admise par tous, des pouvoirs publics aux patrons de presse. Si cela ne suffisait pas, il pourrait se retrancher derrière les interdits qu'une législation spécifique lui oppose. Certes, ces interdits sont des contraintes mais ils peuvent aussi être invoqués comme définissant des situations d'illégalité dans lesquelles nul ne peut l'obliger à s'engager. Qu'un rédacteur en chef commande à un journaliste un papier sur la vie privée de tel homme politique et il s'entendra opposer la loi de 1881. D'ailleurs, la loi prévoyant la responsabilité conjointe du directeur de la publication, on imagine l'hésitation à passer une telle commande.

4 Le comptable, le médecin d'entreprise sont, eux aussi, abrités par la loi ou la coutume.

5 2. Il n'en va pas de même pour les chargés de communication des organisations où l'alternative au refus d'obtempérer est souvent le départ. L'actualité vient de nous en fournir des exemples éclatants. Or, n'importe quel observateur de l'entreprise connait le rôle que l'on fait jouer au responsable de la communication interne lors des restructurations. Pour reprendre l'euphémisme du consultant canadien David Nitkin, « le problème revient à maintenir le moral des employés ». Et, le plus souvent, à développer 
chez eux l'égoïsme de l'élu que le sort du damné indiffère. Maintenir le moral des employés à la veille d'une vague de licenciements impose souvent quelques manquements à l'éthique qui sont de nature à perturber la conscience du communicateur découvrant à ses dépens l'inconfort de la double contrainte.

6 3. Bien sûr, il existe une déontologie qui s'exprime par des codes au respect desquels veillent des associations professionnelles. Mais, dans l'état actuel de la question, ces codes n'ont pas de valeur légale et la clause de conscience n'existe pas ici. Qu'un "dircom» oppose à son patron la Charte d'Athènes et il risque de se voir offrir un billet pour la Grèce. Aller simple. Entendons-nous bien et ne brossons pas un tableau manichéen. Il n'y a pas les méchants patrons et les honnêtes communicateurs. Nombreux sont les chefs d'entreprise qu'une éthique personnelle guide dans l'exercice de leurs responsabilités. Mais rien ne limite l'action des autres et rien ne supplée vraiment à la fragilité du chargé de communication.

7 4. La question se pose donc de la mise au point d'un garde-fou qu'imposeraient des moyens réglementaires. Ce pourrait être une loi ou une convention collective par exemple. Mais, même dans une société libérale, on ne peut laisser s'exercer n'importe comment ces métiers dangereux. Il a fallu longtemps pour que l'exercice de la profession de psychologue fût réglementé, longtemps et beaucoup de dégâts. N'attendons pas que la communication ait assassiné pour instaurer le port d'armes.

8 5. Le Groupe de Recherche en Communication des organisations prend l'initiative de réunir un comité formé de juristes, de professionnels, d'employeurs et de formateurs et qui aura pour objet d'étudier l'opportunité d'une protection réglementaire et les formes que pourrait prendre celle-ci pour peu qu'elle soit souhaitable.

9 Ce qui fut dit fut fait et le 12 avril 1991, Jacques Chaban-delmas présidait, à Bordeaux, la séance inaugurale du Groupe de réflexion sur les conditions d'exercice des professions de communication. Aux représentants du droit, de l'enseignement et de la profession s'étaient jointes des personnalités ayant montré, à des titres divers, intérêt et compétence pour la question.

10 Ce comité d'une douzaine de personnes fortement concernées par le sujet s'est, depuis, réuni régulièrement à Paris. Il a consulté des experts, analysé des textes, passé la jurisprudence au crible de la critique. Pour en arriver à la conclusion que toute réglementation serait probablement préjudiciable aux professionnels. Si les grands directeurs de communication semblent relativement protégés par leur notoriété, les chargés de communication des entreprises et, plus encore, des institutions, paraissent particulièrement vulnérables. Il existe en droit du travail français un motif de renvoi qui pourrait ressortir aux pratiques régaliennes : la perte de confiance. Un chef d'entreprise peut se séparer d'un collaborateur s'il estime ne plus pouvoir lui accorder sa confiance. Récemment, la Présidente de la Croix Rouge française, mise en cause pour avoir facilité, sinon organisé, l'entrée et l'hospitalisation en France d'un leader palestinien soupçonné d'avoir commandité des crimes terroristes sur le sol français, a recouru à ce motif pour renvoyer son directeur de communication. Et la jurisprudence donne raison à un charcutier qui avait licencié son commis en qui il avait perdu confiance... parce qu'il avait dénoncé les agissements, réels, de son patron incorporant de la sciure dans ses saucisses ! On voit la fragilité d'une profession aussi exposée que celle du chargé de communication. 
11 Le groupe de travail s'oriente donc vers l'élaboration de propositions contractuelles qui seraient soumises publiquement aux organisations représentatives des chefs d'entreprise à l'occasion d'une journée de réflexion prévue pour juin 1992 à Bordeaux.

Étude, réflexion, action sont les mots qui résument le mieux les méthodes de travail d'un groupe qui se veut une force de proposition mais aussi un lieu de recherche-action au service d'une profession tout autant que d'un domaine: la communication des organisations.

\section{Composition du groupe}

\section{RÉSUMÉS}

À la suite d'un colloque consacré à " éthique et communication ", le groupe de recherche en communication des organisations a installé une structure de réflexion sur les conditions d'exercice des professions de communication. S'appuyant sur l'étude de textes, la consultation d'experts et l'analyse critique de la jurisprudence, il a été amené à renoncer à l'hypothèse-proposition qui avait justifié sa création et à modifier ses orientations au terme d'une rechercheaction.

\section{AUTEUR}

\section{HUGUES HOTIER}

Professeur à l'Université Michel de Montaigne-Bordeaux 3 où il dirige l'Institut des Sciences de l'Information et de la Communication (ISIC) et le GREC/O. Ses travaux portent 
sur les stratégies de communication des organisations ainsi que sur la communication non-verbale dans le spectacle populaire. Il est régulièrement professeur invité

d'universités canadiennes et est associé aux enseignements et à la recherche en communication de l'Université Hassan II de Casablanca. 